INTERVENTIONAL CARDIOLOGY AND SURGERY

\title{
One year clinical follow up of paclitaxel eluting stents for acute myocardial infarction compared with sirolimus eluting stents
}

\author{
S H Hofma, A T L Ong, J Aoki, C A G van Mieghem, G A Rodriguez Granillo, \\ M Valgimigli, E Regar, P P T de Jaegere, E P McFadden, G Sianos, W J van der \\ Giessen, P J de Feyter, R T Van Domburg, P W Serruys
}

See end of article for authors' affiliations

\section{Correspondence to:} Professor Patrick W Serruys, Thoraxcentre, $\mathrm{Bd}-406, \mathrm{Dr}$ Molewaterplein 40 3015-GD Rotterdam Netherlands; p.w.j.c.serruys@ erasmusmc.nl

Accepted 29 April 2005 Published Online First 9 May 2005
Objective: To compare clinical outcome of paclitaxel eluting stents (PES) versus sirolimus eluting stents (SES) for the treatment of acute ST elevation myocardial infarction.

Design and patients: The first 136 consecutive patients treated exclusively with PES in the setting of primary percutaneous coronary intervention for acute myocardial infarction in this single centre registry were prospectively clinically assessed at 30 days and one year. They were compared with 186 consecutive patients treated exclusively with SES in the preceding period.

Setting: Academic tertiary referral centre.

Results: At 30 days, the rate of all cause mortality and reinfarction was similar between groups $(6.5 \% \mathrm{v}$ $6.6 \%$ for SES and PES, respectively, $p=1.0$ ). A significant difference in target vessel revascularisation (TVR) was seen in favour of SES $(1.1 \% \vee 5.1 \%$ for PES, $p=0.04)$. This was driven by stent thrombosis $(n=4)$, especially in the bifurcation stenting $(n=2)$. At one year, no significant differences were seen between groups, with no late thrombosis and 1.5\% in-stent restenosis (needing TVR) in PES versus no reinterventions in SES $(p=0.2)$. One year survival free of major adverse cardiac events (MACE) was $90.2 \%$ for SES and $85 \%$ for PES ( $p=0.16$ ).

Conclusions: No significant differences were seen in MACE-free survival at one year between SES and PES for the treatment of acute myocardial infarction with very low rates of reintervention for restenosis. Bifurcation stenting in acute myocardial infarction should, if possible, be avoided because of the increased risk of stent thrombosis.
$T$ he efficacy of drug eluting stents to treat coronary artery stenosis in stable patients has been proved in recent trials with single digit restenosis rates for non-complex

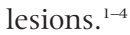

The potential risk of higher thrombogenicity, however, has led to prolonged antiplatelet treatment and cautious use of these stents for acute coronary syndromes. We have recently shown that the use of sirolimus eluting stents (SES) for acute myocardial infarction is safe and not associated with higher thrombogenicity. The safety and efficacy of paclitaxel eluting stents (PES) in this setting has not been reported yet.

A recent meta-analysis clearly showed the benefit of primary percutaneous coronary intervention (PCI) over administration of thrombolytics for the treatment of acute myocardial infarction. ${ }^{6}$ The superiority of (bare metal) stenting over balloon angioplasty has been well documented in the setting of acute myocardial infarction.

We report the one year clinical outcome of a consecutive patient cohort treated solely with PES in the setting of primary PCI for acute ST elevation myocardial infarction. We compared their outcome with that of an earlier published patient population treated with SES.

\section{METHODS}

Patients

Since 16 February 2003, PES (Taxus; Boston Scientific, Galway, Ireland) has been implemented in our hospital as the default stent for all patients. Data were collected for the T-SEARCH (Taxus stent evaluated at Rotterdam Cardiology Hospital) registry. ${ }^{8}$ This is a prospective single centre registry set up with the main purpose of evaluating the safety and efficacy of PES implantation for patients treated in daily practice. Until September 2003, 136 consecutive patients received exclusively PES in the setting of primary PCI for acute myocardial infarction. All patients were enrolled in the analysis including patients in cardiogenic shock (defined as persistent systolic blood pressure $<90 \mathrm{~mm} \mathrm{Hg}$ or the need for vasopressors or intra-aortic balloon pumping required to maintain blood pressure $>90 \mathrm{~mm} \mathrm{Hg}$ with evidence of end organ failure and increased left ventricular filling pressures). Patients who underwent rescue PCI after failed thrombolysis were not included in this study.

One year clinical outcome was compared with the one year data from the first 186 patients treated exclusively with SES in the setting of primary PCI for acute myocardial infarction between April 2002 and January 2003, when SES was the default stent in our centre. ${ }^{5}$

This study protocol was approved by the local ethics committee, and written informed consent was obtained from every patient.

\section{Treatment strategy and definitions}

The interventional strategy and use of glycoprotein IIb/IIIa inhibitors was left entirely to the discretion of the operator. Clopidogrel was recommended for six months, in addition to

\footnotetext{
Abbreviations: ASA, acetylsalicylic acid; MACE, major adverse cardiac events; PCl, percutaneous coronary intervention; PES, paclitaxel eluting stents; SES, sirolimus eluting stents; T-SEARCH, Taxus stent evaluated at Rotterdam Cardiology Hospital; TIMI, thrombolysis in myocardial infarction; TVR, target vessel revascularisation
} 
lifelong acetylsalicylic acid (ASA) $80 \mathrm{mg}$. The loading dose of $300 \mathrm{mg}$ clopidogrel was given before the intervention. If the patient was not taking ASA, $250 \mathrm{mg}$ of intravenous ASA was given at the start of the procedure.

The occurrence of major adverse cardiac events (MACE) was evaluated at one year. MACE were all cause mortality, non-fatal myocardial infarction, and target lesion revascularisation or target vessel revascularisation (TVR).

Reinfarction was defined as new symptoms or new ECG changes in association with an increase in creatine kinase $\mathrm{MB}$ fraction concentrations of 1.5 times the previous value if measured within 48 hours or $>3$ times the upper normal limit if measured $>48$ hours after the index infarction. Target lesion revascularisation was defined as a repeat intervention (surgical or percutaneous) to treat a luminal stenosis within the stent or in the $5 \mathrm{~mm}$ distal or proximal segments adjacent to the stent. TVR was defined as a repeat intervention driven by any lesion located in the same epicardial vessel treated at the index procedure. Thrombotic stent occlusion was angiographically documented as a complete occlusion (TIMI (thrombolysis in myocardial infarction) flow grade 0 or 1 ) or a flow limiting thrombus (with TIMI flow 1 or 2 ) of a previously successfully treated artery.

\section{Follow up}

All patients were clinically followed up. Repeat angiography was clinically driven by symptoms or signs of ischaemia. Information about in-hospital outcomes was obtained from
Table 2 Major adverse cardiac events at 30 days and one year

\begin{tabular}{|c|c|c|c|}
\hline & $\begin{array}{l}\text { SES } \\
(n=186)\end{array}$ & $\begin{array}{l}\text { PES } \\
(n=136)\end{array}$ & p Value* \\
\hline \multicolumn{4}{|l|}{ 0-1 month } \\
\hline Death & $5.9 \%$ & $5.9 \%$ & 1.0 \\
\hline Death or re-Ml & $6.5 \%$ & $6.6 \%$ & 1.0 \\
\hline TLR & $1.1 \%$ & $4.4 \%$ & 0.07 \\
\hline TVR & $1.1 \%$ & $5.1 \%$ & 0.04 \\
\hline Death, re-MI, or TVR & $7.5 \%$ & $10.3 \%$ & 0.4 \\
\hline Stent thrombosis & $0 \%$ & $2.9 \%$ & 0.03 \\
\hline \multicolumn{4}{|l|}{ 0-12 months } \\
\hline Death & $8.1 \%$ & $8.1 \%$ & 1.0 \\
\hline Death or re-MI & $9.2 \%$ & $10.3 \%$ & 0.7 \\
\hline TLR & $1.1 \%$ & $5.9 \%$ & 0.02 \\
\hline TVR & $1.1 \%$ & $6.6 \%$ & 0.01 \\
\hline Death, re-MI, or TVR & $9.7 \%$ & $14.7 \%$ & 0.22 \\
\hline Stent thrombosis & $0 \%$ & $2.9 \%$ & 0.03 \\
\hline
\end{tabular}

our institutional electronic clinical database and by review of the hospital records for patients discharged to referring hospitals (patients were referred from 14 local hospitals). Postdischarge survival status was obtained from the municipal civil registries at one, six, and 12 months. Data on all repeat interventions (surgical and percutaneous) and repeat

\begin{tabular}{|c|c|c|c|}
\hline & SES $(n=186)$ & PES $(n=136)$ & $\mathrm{p}$ Value \\
\hline Men & $74.7 \%$ & $83.8 \%$ & 0.06 \\
\hline Age (years) & $59.7(11.7)$ & $59.2(12.1)$ & 0.7 \\
\hline Diabetes & $10.8 \%$ & $3.7 \%$ & 0.02 \\
\hline Current smoking & $45.7 \%$ & $44.9 \%$ & 0.9 \\
\hline Hypercholesterolaemia & $33.9 \%$ & $30.1 \%$ & 0.5 \\
\hline Hypertension & $24.2 \%$ & $20.6 \%$ & 0.5 \\
\hline Previous myocardial infarction & $14.4 \%$ & $10.6 \%$ & 0.4 \\
\hline Previous PCl & $6.5 \%$ & $5.9 \%$ & 1.0 \\
\hline Previous CABG & $1.6 \%$ & $2.2 \%$ & 0.7 \\
\hline Coronary artery disease & & & 0.9 \\
\hline 1 vessel & $54.8 \%$ & $52.2 \%$ & \\
\hline 2 vessel & $27.4 \%$ & $28.7 \%$ & \\
\hline 3 vessel & $17.7 \%$ & $19.1 \%$ & \\
\hline Cardiogenic shock & $13.4 \%$ & $11.8 \%$ & 0.7 \\
\hline Time from symptom onset to $\mathrm{PCl}$ (hours) & $3.2(1.9)$ & $3.1(2.4)$ & 0.7 \\
\hline Infarct related vessel & & & 0.6 \\
\hline LAD & $52.7 \%$ & $51.5 \%$ & \\
\hline $\mathrm{LCx}$ & $8.2 \%$ & $8.8 \%$ & \\
\hline RCA & $37.4 \%$ & $36.0 \%$ & \\
\hline Left main stem & $1.6 \%$ & $2.2 \%$ & \\
\hline Saphenous vein graft & $0 \%$ & $1.5 \%$ & \\
\hline Bifurcation lesion & $8.6 \%$ & $9.6 \%$ & 0.8 \\
\hline Number of vessels treated & & & 1.0 \\
\hline 1 & $84.9 \%$ & $86.0 \%$ & \\
\hline$>1$ & $15.1 \%$ & $14.0 \%$ & \\
\hline TIMI flow baseline grade & & & 0.4 \\
\hline $0-1$ & $73.1 \%$ & $78.7 \%$ & \\
\hline 2 & $16.5 \%$ & $11.0 \%$ & \\
\hline 3 & $10.4 \%$ & $10.3 \%$ & \\
\hline TIMI flow final grade & & & 0.7 \\
\hline $0-1$ & $2.1 \%$ & $2.2 \%$ & \\
\hline 2 & $14.8 \%$ & $11.8 \%$ & \\
\hline 3 & $83.0 \%$ & $86.0 \%$ & \\
\hline Number of stents & $1.9(1.2)$ & $1.8(1.1)$ & 0.4 \\
\hline Total stented length (mm) & $34.7(23.5)$ & $35.9(22.9)$ & \\
\hline Mean nominal stent diameter $(\mathrm{mm})$ & $2.89(0.16)$ & $3.11(0.33)$ & $<0.001$ \\
\hline Glycoprotein Ilb/Illa inhibitor & $36.6 \%$ & $55.1 \%$ & 0.001 \\
\hline Peak CK (IU) & $3126(3126)$ & $3234(2567)$ & 0.8 \\
\hline Peak CK-MB (IU) & $296(255)$ & $359(330)$ & 0.2 \\
\hline
\end{tabular}


hospitalisations were prospectively collected during follow up. Questionnaires regarding anginal status and medication use were sent to all living patients at six and 12 months. Referring physicians and institutions were contacted for additional information if required.

\section{Statistical analysis}

Continuous variables are presented as mean (SD) and were compared by Student's unpaired $t$ test. Categorical variables are presented as counts and percentages and compared by Fisher's exact test. All statistical tests were two tailed. The cumulative incidence of adverse events was estimated according to the Kaplan-Meier method and compared by the log rank test. Cox proportional hazards survival models were used to assess risk reduction. Multivariate analyses were performed to identify independent predictors of long term MACE. Significant baseline and procedural characteristics at univariate analysis (tested variables: age, diabetes, cardiogenic shock, multivessel disease, left main stem as the infarct related artery, postprocedural TIMI flow, bifurcation treatment, multivessel treatment, and duration of pain), sex, and stent type were tested for their multivariate predictive value. The first model was built by backwards stepwise variable selection with the exit criteria set at the $\mathrm{p}=0.1$ level; the final model was built by forcing stent type together with all significant predictors.

\section{RESULTS}

In total 136 patients were treated with PES only in the setting of primary PCI for acute myocardial infarction in the study period. These patients were compared with 186 patients treated with SES for the same indication in the period before our centre switched to PES as the default strategy. Follow up of the 186 patients with SES from our earlier report ${ }^{5}$ was extended from 300 days to one year for the comparison. At one year after the procedure, follow up was available for $98.4 \%$ of patients.

Table 1 lists baseline characteristics. Fewer PES patients had diabetes $(3.7 \% \vee 10.8 \%, \mathrm{p}=0.02)$. PES patients had a larger nominal stent size $(3.11 \vee 2.89 \mathrm{~mm}, \mathrm{p}<0.001)$ and a higher percentage of periprocedural glycoprotein IIb/IIIa inhibitor use $(55.1 \% v 36.6 \%, p=0.001)$. Despite inclusion of consecutive patients in both SES and PES groups, the prevalence of diabetes differed significantly. This does not reflect selection bias. The smaller nominal stent size in the SES group reflects the unavailability of SES $>3.0 \mathrm{~mm}$ at the time of the study.

MACE were analysed at one month and one year. Table 2 shows the results. No significant difference was seen in death and death or reinfarction between the two groups either in the first month or at late follow up. However, a significant

\begin{tabular}{|c|c|c|c|}
\hline & SES $(n=16)$ & PES $(n=13)$ & p Value \\
\hline Main branch stent only & $3(18.8 \%)$ & $3(23.1 \%)$ & $0.4^{*}$ \\
\hline Crush & $2(12.5 \%)$ & $4(30.8 \%)$ & \\
\hline Culotte & 0 & $1(7.7 \%)$ & \\
\hline$T$ stent & $9(56.3 \%)$ & $3(23.1 \%)$ & \\
\hline V stent & $2(12.5 \%)$ & $2(15.4 \%)$ & \\
\hline Final kissing balloon & $6(42.9 \%)$ & $8(61.5 \%)$ & 0.3 \\
\hline
\end{tabular}

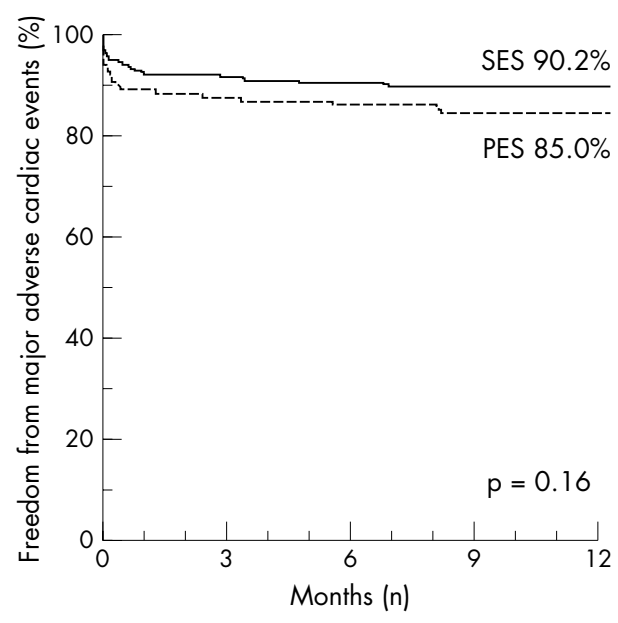

Figure 1 Survival free of death, reinfarction, or target vessel revascularisation of patients who received a sirolimus eluting stent (SES) versus a paclitaxel eluting stent (PES) by Kaplan-Meier estimate.

difference in TVR was seen in favour of SES, which was already apparent at 30 days driven by stent thrombosis.

Six of seven patients with TVR within 30 days in the PES group received target lesion reintervention. Of these, four interventions were necessary because of subacute stent thrombosis (table 3). Only one of these patients had been treated with periprocedural glycoprotein IIb/IIIa inhibitor during the index procedure.

Two of four stent thromboses were in patients treated with bifurcation lesions (one patient with crush bifurcation stenting without kissing balloon postdilatation but with periprocedural glycoprotein IIb/IIIa inhibitor and one patient with $\mathrm{T}$ stent bifurcation stenting without kissing balloon postdilatation and without glycoprotein IIb/IIIa inhibitor). The two remaining cases were caused by stent underexpansion, diagnosed at reintervention.

\begin{tabular}{|lllll}
\hline \multicolumn{5}{l}{ Table 3 Characteristics of individual cases of PES stent thrombosis } \\
\hline \multicolumn{5}{l}{ Patient number } \\
\cline { 2 - 6 } & $\mathbf{1}$ & $\mathbf{2}$ & $\mathbf{3}$ & $\mathbf{4}$ \\
\hline Patient age (years) & 59 & 50 & 52 & 47 \\
Sex & Male & Male & Female & Female \\
Time to thrombosis & 1 hour & 4 days & 4 days & 6 days \\
Lesion type (AHA classification) & B2 & B2 & C & C \\
Number of stents & 1 & 1 & 2 & 2 \\
Total stent length (mm) & 28 & 24 & 44 & 36 \\
Smallest stent diameter (mm) & 3.0 & 3.5 & 2.25 & 2.5 \\
Treated vessel & RCA & LAD & LCx, OMCx LAD, 1 st diagonal \\
Bifurcation stenting & No & No & T stent & Crush \\
Kissing balloon postdilatation & NA & NA & No & No \\
Abciximab during index procedure & No & No & No & Yes \\
\hline AHA, American Heart Association; NA, not applicable; OMCx, obtuse marginal branch of the left circumflex \\
artery.
\end{tabular}




\begin{tabular}{|c|c|c|c|}
\hline Independent predictor & HR & $95 \% \mathrm{Cl}$ & $\mathrm{p}$ Value \\
\hline \multicolumn{4}{|l|}{ TIMI flow grade } \\
\hline 3 (reference) & 1.00 & NA & NA \\
\hline 2 & 2.90 & 0.86 to 9.77 & 0.09 \\
\hline 0 or 1 & 10.24 & 2.61 to 40.13 & 0.001 \\
\hline Cardiogenic shock & 4.38 & 1.63 to 11.8 & 0.003 \\
\hline Diabetes mellitus & 4.77 & 1.61 to 14.1 & 0.005 \\
\hline Duration of pain (per hour increment) & 1.17 & 0.98 to 1.39 & 0.08 \\
\hline Multivessel disease & 2.13 & 0.79 to 5.78 & 0.14 \\
\hline Use of PES & 2.07 & 0.78 to 5.48 & 0.14 \\
\hline
\end{tabular}

The bifurcation stenting percentage was not significantly different between groups $(8.6 \% \vee 9.6 \%$ for SES and PES, respectively, $\mathrm{p}=0.8$ ). Although across all strategies no significant difference was found in bifurcation lesion treatment between SES and PES patients, a trend was seen towards more crush stenting and less $\mathrm{T}$ stenting in PES patients (table 4).

MACE-free survival at 12 months was $90.2 \%$ for SES and $85 \%$ for PES patients ( $p=0.16$, by Kaplan-Meier estimate) (fig 1).

On multivariate analysis, stent type was not an independent predictor of MACE at one year and, when forced into the model of significant predictors, remained non-significant $(\mathrm{p}=0.14)($ table 5$)$. However, independent predictors were TIMI flow 0 or 1 (hazard ratio (HR) 10.2), cardiogenic shock (HR 4.4), and diabetes mellitus (HR 4.8).

\section{DISCUSSION}

The main finding of this sequential registry report is that patients treated with drug eluting stents for acute myocardial infarction have a very low rate of repeat revascularisation for restenosis at one year's follow up.

Although no significant difference in MACE at one year was found between the two drug eluting stents, a trend to worse outcome was seen in the patients treated with PES, despite more favourable baseline characteristics such as less diabetes, higher use of glycoprotein IIb/IIIa inhibitors, and larger nominal stent diameter.

\section{Short term follow up}

The largest difference between the groups was TVR in the first 30 days. These were mainly driven by stent thrombosis.

With respect to these observations of two of 13 stent thromboses in bifurcation lesions and two of 123 in nonbifurcation lesions, it seems prudent to try to avoid using two stents for bifurcation treatment in acute myocardial infarction. If this is unavoidable, the risk for stent thrombosis may be reduced by kissing balloon postdilatation and periprocedural glycoprotein IIb/IIIa inhibitor. In a separate study of 2500 patients we confirmed that bifurcation stenting in acute myocardial infarction was a significant predictor of stent thrombosis and conferred a 13-fold increase in risk. ${ }^{9}$ It may be advisable to keep procedures short and simple for patients undergoing angioplasty for acute myocardial infarction.

The overall rate of stent thrombosis was $1.2 \%$ (four of 322) for drug eluting stent use in acute myocardial infarction. This is comparable with the stent thrombosis rate with bare stents $^{9}{ }^{10}$ and drug eluting stents ${ }^{9}$ used in the treatment of patients for stable coronary lesions.

\section{Long term follow up}

Between 30 days and one year two patients treated with PES were referred for TVR, both for in-stent restenosis (1.5\%), compared with no additional interventions for the SES patients.

No late stent thrombosis was diagnosed in either group. In this study, the risk for late stent thrombosis after stopping clopidogrel, which was prescribed for six months for the PES and 3-6 months for the SES group, does not seem to be increased for treatment of patients with acute coronary syndromes with drug eluting stents. It is important that, to address this potential problem conclusively, larger studies specifically looking at this end point be performed. Furthermore, until more is known, complete cessation of antiplatelets should be avoided if possible to avoid the risk of late thrombosis, as McFadden $e t a l^{11}$ recently pointed out.

Early and one year mortality was identical in both groups ( $5.9 \%$ at 30 days and $8.1 \%$ at one year for SES and PES). This is very comparable with earlier studies ${ }^{6}$ despite the presence of cardiogenic shock in $12 \%$ of patients and multivessel disease in almost half. As shown before, mortality is not changed by the use of drug eluting stents. ${ }^{5}$ Their benefit is reduction of reintervention as in elective PCI.

The recommendations in the most recent National Institute for Health and Clinical Excellence guidelines explicitly exclude acute myocardial infarction and lesions with visible thrombus as indications for use of drug eluting stents. ${ }^{12}$ Our results are reassuring and do not indicate that patients with acute myocardial infarction should be denied the benefit of the very low reintervention rates with drug eluting stents.

\section{Conclusions}

The use of PES for the treatment of acute myocardial infarction seems safe. No significant differences were seen with the results of SES at one year's follow up with a very low rate of reintervention for restenosis. However, a trend towards more early reinterventions was evident, mainly due to stent thrombosis. Bifurcation stenting should be avoided in the setting of primary PCI, if possible.

\section{Authors' affiliations}

S H Hofma, A T L Ong, J Aoki, C A G van Mieghem, G A Rodriguez Granillo, M Valgimigli, E Regar, P P T de Jaegere, E P McFadden, G Sianos, W J van der Giessen, P J de Feyter, R T Van Domburg, P W Serruys, Thoraxcentre, Erasmus Medical Centre, Rotterdam, the Netherlands

Study supported by the Erasmus MC, Rotterdam, and by unrestricted institutional grants from Boston Scientific Corporation and Cordis, a Johnson and Johnson company.

\section{REFERENCES}

1 Morice MC, Serruys PW, Sousa JE, et al, for the RAVEL study group. A randomized comparison of a sirolimus-eluting stent with a standard stent for revascularization. N Engl J Med 2002;346:1773-80. 
2 Moses JW, Leon MB, Popma JJ, et al, for the SIRIUS investigators. Sirolimuseluting stents versus standard stents in patients with stenosis in a native coronary artery. N Engl J Med 2003;349:1315-23.

3 Colombo A, Drzewiecki J, Banning A, et al, for the TAXUS II study group. Randomized study to assess the effectiveness of slow- and moderate-release polymer-based paclitaxel-eluting stents for coronary artery lesions. Circulation 2003; 108:788-94.

4 Stone GW, Ellis SG, Cox DA, et al, for the TAXUS-IV investigators. A polymer based, paclitaxel-eluting stent in patients with coronary artery disease. N Engl J Med 2004:350:221-31.

5 Lemos PA, Saia F, Hofma SH, et al. Short- and long-term clinical benefit of sirolimus-eluting stents compared to conventional bare stents for patients with acute myocardial infarction. J Am Coll Cardiol 2004;43:704-8.

6 Keeley EC, Boura JA, Grines CL. Primary angioplasty versus intravenous thrombolytic therapy for acute myocardial infarction: a quantitative review of 23 randomised trials. Lancet 2003;361:13-20.

7 Stone GW, Grines CL, Cox DA, et al, for the Controlled Abciximab and Device Investigation to Lower Late Angioplasty Complications (CADILLAC) investigators. Comparison of angioplasty with stenting, with or without abciximab, in acute myocardial infarction. N Engl J Med 2002;346:957-66.

8 Ong AT, Serruys PW, Aoki J, et al. The unrestricted use of paclitaxel- versus sirolimus-eluting stents for coronary artery disease in an unselected population: one-year results of the Taxus-stent evaluated at Rotterdam Cardiology Hospital (T-SEARCH). J Am Coll Cardiol 2005;45:1135-41.

9 Ong AT, Hoye A, Aoki J, et al. 30-Day incidence and 6-month clinical outcome of thrombotic stent occlusion following bare metal, sirolimus or paclitaxel stent implantation. J Am Coll Cardiol 2005:45:947-53.

10 Cutlip DE, Baim DS, Ho KK, et al. Stent thrombosis in the modern era: a pooled analysis of multicenter coronary stent clinical trials. Circulation 2001;103:1967-71

11 McFadden EP, Stabile E, Regar E, et al. Late thrombosis in drug-eluting coronary stents after discontinuation of antiplatelet therapy. Lancet 2004:364:1519-21.

12 Dillon A, chief executive. Guidance on the use of coronary artery stents. Technology appraisal 71;7:7.3.2. October 2003. http://www.nice.org.uk/ pdf/TA71_coronaryarterystents_fullguidancepdf (accessed 16 January 2005)

\section{IMAGES IN CARDIOLOGY}

\section{Diabetic keto-acidosis and hyperkalaemia induced pseudo-myocardial infarction}

$\mathrm{S}$ T segment elevation on ECG has other causes apart from myocardial infarction (MI) and in the thrombolytic treatment era, this may expose the patient to unnecessary drug treatment or invasive procedures that have the potential risk of complications.

A 30 year old insulin dependent diabetic man was treated for severe diabetic ketoacidosis. He was a smoker with a 15 year history of diabetes mellitus. His potassium on admission was $6.5 \mathrm{mmol} / \mathrm{l}$ and his ECG showed tall, peaked T wave (panel A). Eight hours following admission, ST segment elevation was noted on the monitor and an inferolateral acute MI pattern (panel B) was confirmed by ECG. The patient had no chest pain but was thrombolysed with tenecteplase with no resolution of his ST segment elevation; his potassium at the time of the ST elevation was $6.9 \mathrm{mmol} / \mathrm{l}$. He was referred to our centre for coronary angiography, which surprisingly was entirely normal but with poor left ventricular function. Cardiac troponin $\mathrm{T}$ was raised at $2.54 \mu \mathrm{g} / \mathrm{l}$ and the $\mathrm{ST}$ segment elevation was improving gradually. He was treated medically and made a good recovery and was discharged home seven days later.

Hyperkalaemia may produce multiple ECG abnormalities, including ST segment elevation and pseudoinfarct pattern with resolution of these abnormalities on correcting the hyperkalaemia. When faced with a patient with hyperkalaemia, ST segment elevation may pose a diagnostic and management dilemma regarding the use of thrombolysis. We suggest that while measures are undertaken to correct the metabolic derangement, an immediate referral for coronary angiography should be the first approach. Alternatively, bedside echocardiography, to demonstrate any regional wall motion abnormalities, and cardiac troponin measurement can be used where angiography is not available.

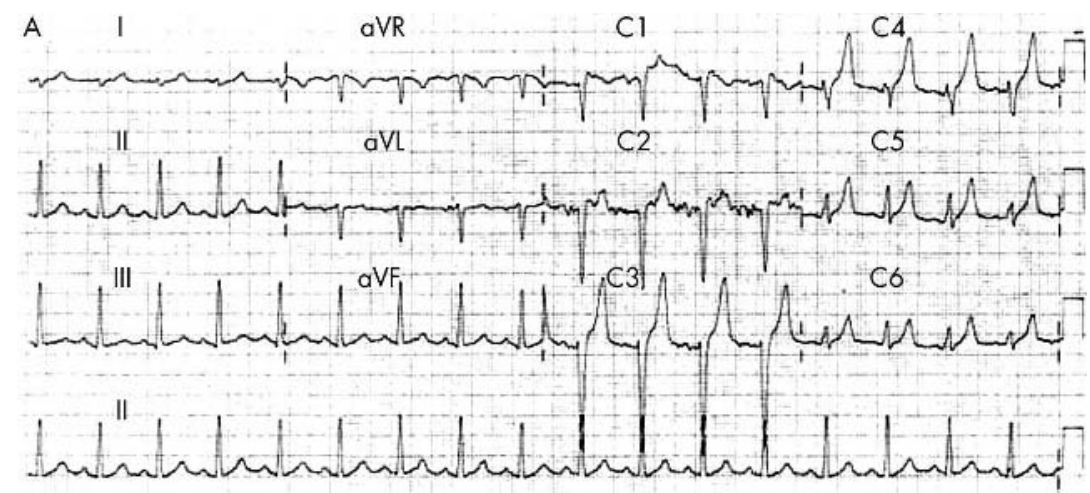

B

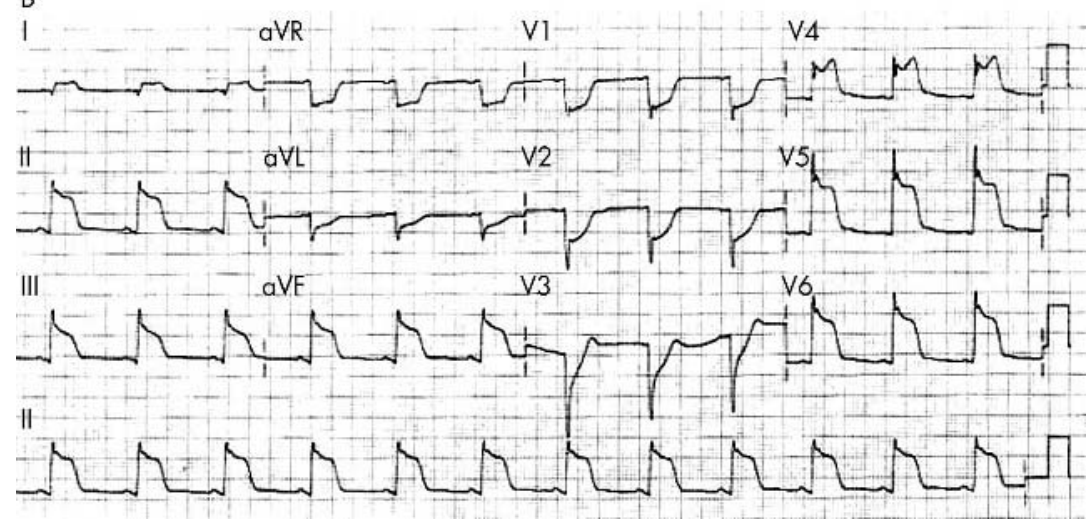

In case of doubts, thrombolysis should not be withheld, as it remains largely safe with life saving effects.

M Egred

W L Morrison

m.egred@ctc.nhs.uk 